Pereira, Sérgio (2020). Discursos expositivos enquanto recurso pedagógico: análise de uma experiência escolar desenvolvida entre 2006 e 2017. In Alice Duarte (ed.), Seminários DEP/FLUP vol. 1. Porto: Universidade do Porto, Faculdade de Letras/DCTP, p. 118-140. https://doi.org/10.21747/9789898969682/seminariosv1a6

\title{
Discursos expositivos enquanto recurso pedagógico: análise de uma experiência escolar desenvolvida entre 2006 e 2017
}

\author{
Sérgio Pereira \\ FLUP/Doutoramento em Estudos do Património (DEP) \\ sbvpereira@gmail.com
}

\section{Resumo}

O presente capítulo elabora uma reflexão sobre a utilização dos discursos expositivos enquanto recursos pedagógicos em ambiente escolar. Focando a experiência docente do autor, o capítulo procura mostrar como as tradicionais visitas a museus começaram a ser complementadas com a elaboração progressiva de atividades expositivas dentro da escola, alargando no tempo a experiência museal, o que contribuiu para a aprendizagem dos estudantes envolvidos e para a valorização das atividades culturais entre a comunidade escolar.

Palavras-chave - Exposição; Escola; Pedagogia; Museu; Nova Museologia

\section{Expository discourses as a pedagogical tool: analysis of a school experience developed between 2006 and 2017}

\begin{abstract}
This chapter elaborates a reflection about using the expository discourses as educational resources in a school context. Focusing the teaching experience of the author, the chapter aims to show how the traditional visits to museums began to be complemented by the progressive elaboration of expositive activities within the school, extending the museum experience in time, which contributed to the students learning and to the valorisation of cultural activities among the school community.
\end{abstract}

Keywords: Exhibition; School; Pedagogy; Museum; New Museology 
Pereira, Sérgio (2020). Discursos expositivos enquanto recurso pedagógico: análise de uma experiência escolar desenvolvida entre 2006 e 2017. In Alice Duarte (ed.), Seminários DEP/FLUP vol. 1. Porto: Universidade do Porto, Faculdade de Letras/DCTP, p. 118-140. https://doi.org/10.21747/9789898969682/seminariosv1a6

\section{Introdução}

Encontro-me atualmente a frequentar um doutoramento com especialização em Museologia integrado num programa doutoral pluridisciplinar centrado nas questões do património. Foi no âmbito deste ciclo de estudos que surgiu o Seminário Discursos Expositivos: Como, Porquê, Para Quem $?^{1}$ ao qual se associa a presente publicação, um evento focado em questões relacionadas com os discursos expositivos em contexto museológico, sendo este texto a base da minha intervenção. Assim, contrariando a lógica de me focar nos discursos expositivos diretamente enquadráveis com o objeto de estudo relativo ao meu projeto de investigação, decidi focar-me na minha anterior experiência profissional relacionada com o ensino/aprendizagem. Com efeito, nos mais de dez anos em que fui docente no ensino secundário fui desenvolvendo um trabalho em torno dos discursos expositivos aplicados ao contexto educacional e pedagógico. Trata-se de uma experiência desenvolvida num contexto profissional concreto, mas que não me impediu o desenvolvimento progressivo do interesse por temáticas que me encaminharam para esta etapa académica atual.

Pretende-se neste exercício estabelecer uma ponte entre a(s) prática(a) desenvolvidas enquanto docente e as temáticas dos museus, das exposições e da utilização do património em contexto educativo, cultural e turístico. Neste sentido, este texto orienta-se em torno de três ideias fundamentais. A primeira, enquadrar em termos evolutivos a componente educativa na génese do espaço museológico. Segundo, documentar a experiência de trabalho desenvolvida enquanto docente através da explicação das atividades de carater expositivo desenvolvidas num contexto pedagógico (quer em museus visitados, quer no próprio espaço escolar). Por último, situar esta experiência de trabalho nas discussões contemporâneas em torno do papel do museu na sociedade, nomeadamente quanto ao público escolar.

\footnotetext{
${ }^{1}$ O Seminário DEP decorreu em 02.11.2019 na Faculdade de Letras da Universidade do Porto, organizado pelo 20 ano do Doutoramento em Estudos do Património (Departamento de Ciências e Técnicas do Património).
} 
Pereira, Sérgio (2020). Discursos expositivos enquanto recurso pedagógico: análise de uma experiência escolar desenvolvida entre 2006 e 2017. In Alice Duarte (ed.), Seminários DEP/FLUP vol. 1. Porto: Universidade do Porto, Faculdade de Letras/DCTP, p. 118-140. https://doi.org/10.21747/9789898969682/seminariosv1a6

\section{O conceito de museu e a sua dimensão educativa}

Desde o seu surgimento até à atualidade, o museu foi-se reorganizando em termos de espaço físico e de papel social, ao encontro das diferentes visões culturais dos períodos históricos. Porém, o próprio conceito de museu nunca descurou a sua ligação à componente educativa. Desde logo, a própria origem do termo museu está associada às ditas culturas clássicas onde surgem algumas das (ainda hoje) ideias centrais associadas a estas instituições: a associação a espaços de memória e de conhecimento ${ }^{2}$. Porém, é nos finais da Idade Média e no Renascimento que o desenvolvimento do colecionismo concebeu a primeira ideia de espaço expositivo, neste caso para a certificação de factos, comprovando e divulgando conhecimento, com uma forte associação à afirmação de poder de quem detinha as coleções ${ }^{3}$. Trata-se da criação de gabinetes de curiosidades e de coleções privadas, espólios reunidos em plataformas permanentes e semipúblicas para a profissionalização das classes eruditas através de uma educação informal (Nunes, 2010). Numa fase temporal mais próxima, o século XIX vê definir a ideia de museu ligado ao Estado-Nação, dando um carácter mais politizado à instituição museológica, que se torna instrumento político do Estado para instruir o seu povo ${ }^{4}$. Também nesta altura se definem várias tipologias de museus (de arte, arqueologia, ciências naturais, história, ciência e técnica e etnografia), reforçandose a especialização das instituições em diferentes áreas científicas e continuando a fornecer-Ihes um importante cunho educacional. Começam igualmente a ser discutidas

\footnotetext{
2 O termo "museu" surge do latim museum, termo derivado do grego antigo mouseion que na mitologia da Grécia Antiga significaria templo das musas, as deusas da memória filhas de Zeus. Mais tarde, o termo foi utilizado pela dinastia ptolemaica no Egipto para definir o lugar ou edifício destinado ao estudo, a um espaço de conhecimento e de acesso ao saber (Filho, 2006: 7; Hernández, 2006: 22; Soto; 2014).

${ }^{3}$ Os primórdios dos museus no sentido colecionista surgem com os gabinetes de curiosidades e as galerias dos reis, aristocratas e burgueses. Os primeiros surgiram na era das Viagens de Descoberta europeias, apresentavam coleções de espécimes naturais relativos aos (então) três reinos da Natureza (zoologia, botânica e mineralogia) e objetos exóticos provenientes de povos não-europeus com o objetivo de representar o mundo encontrado e certificar o poder dos colonizadores sobre os territórios ocupados. As coleções de tesouros e de objetos artísticos atestavam o poder dos seus possuidores e difundiam o conhecimento e a cultura entre as restritas elites que as podiam observar (Filho, 2006; Soto; 2014).

${ }^{4}$ Com o surgir dos movimentos nacionalistas na Europa surgem os museus nacionais, num quadro sociopolítico que os torna em espaços de representação simbólica da nação. O museu veicula um discurso ideológico onde o seu objetivo maior é o de consciencializar o "povo" sobre a sua identidade e valores culturais (Mendes; 2013: 110-113).
} 
Pereira, Sérgio (2020). Discursos expositivos enquanto recurso pedagógico: análise de uma experiência escolar desenvolvida entre 2006 e 2017. In Alice Duarte (ed.), Seminários DEP/FLUP vol. 1. Porto: Universidade do Porto, Faculdade de Letras/DCTP, p. 118-140. https://doi.org/10.21747/9789898969682/seminariosv1a6

nesta época as funções fundamentais do museu: colecionar objetos, criar arte, dar prestígio ao país, proteger o património cultural e, também, educar.

Durante os períodos históricos aqui traçados em linhas gerais desenvolveu-se a dita Museologia Tradicional: entre os séculos XVIII e XIX e a primeira metade do século XX. Neste largo período, a forma de atuar dos museus refletia um contexto de pensamento no qual as leituras sobre os diversos factos assumiam um estatuto de conhecimento verdadeiro e universal. Assim, as práticas fundadoras em torno do património cultural e da museologia difundiam o que era entendido como evidências indiscutíveis da realidade: esta museologia destacava a especificidade, a antiguidade e a identidade nacional, por intermédio dos monumentos e dos objetos salvaguardados; a posição da nação na hierarquia de poder num cenário internacional; a superioridade dos grupos sociais capacitados para a fruição do património cultural. Estes museus desenvolviam exposições permanentes com uma quase ausência de ligação à investigação científica (exceto quanto à "descoberta" de bens patrimoniais e à verificação da autenticidade destes) e tinham uma dimensão educacional limitada devido à inexistência de divulgação externa para o acolhimento diferenciado de públicos. Verificava-se uma coincidência entre as perspetivas ideológicas dos museus e os seus visitantes, adultos membros das classes médias e altas (Nunes; 2010; Bennett, 1995).

No contexto pós 2a Guerra Mundial e em consequência dos seus efeitos, a história passou a ser reconstituída e analisada, o discurso expositivo repensado em termos de suportes e em termos de conteúdo ${ }^{5}$. Dá-se o surgimento da museologia enquanto área científica nas universidades e a intensificação das discussões geradas pela designada Nova Museologia, um novo movimento contestatário abrangente, enquadrado nos pressupostos do período moderno que vem questionar os pressupostos da museologia tradicional ${ }^{6}$. À medida que o século XX alterou os regimes

\footnotetext{
${ }^{5}$ Assumiu-se o carácter político do conhecimento, por definição condicionado, de validade parcial e temporária. Apostou-se na valorização da pluralidade da documentação exposta através de diferentes formatos, no contributo para o debate cultural e cívico; na inclusão de temáticas até então consideradas subversivas ou irrelevantes numa visão institucional mais diversa e globalizada (Nunes, 2010; Bennett, 1995).

${ }^{6}$ As críticas aos pressupostos do paradigma moderno começam por se desencadear nos anos de 1930. 0 reconhecimento das limitações do conhecimento científico e tecnológico vêm ponderar a conjugação
} 
Pereira, Sérgio (2020). Discursos expositivos enquanto recurso pedagógico: análise de uma experiência escolar desenvolvida entre 2006 e 2017. In Alice Duarte (ed.), Seminários DEP/FLUP vol. 1. Porto: Universidade do Porto, Faculdade de Letras/DCTP, p. 118-140. https://doi.org/10.21747/9789898969682/seminariosv1a6

políticos dos países, as mudanças em contexto museológico foram-se verificando sobretudo em ambientes mais democráticos ${ }^{7}$.

Em 1946, surge o Conselho Internacional dos Museus (ICOM) que vem reforçar a dimensão pedagógica destes, referindo a educação, o estudo e o deleite na nova definição de museu que propõe ${ }^{8}$. A Nova Museologia corporiza, assim, um movimento de renovação de largo espetro, de abrangência teórica e metodológica, iniciado nos anos de 1960, mas do qual ainda se esperam na atualidade os efeitos da defendida renovação (Duarte, 2013). Em concreto, este novo movimento vem desconstruir a rigidez do espaço museológico em termos físicos, fazendo nascer novas tipologias como os ecomuseus, os museus integrais e os museus de comunidade (ICOM, 1984). Quanto ao papel social e educacional, em foco neste texto, vem também defender em termos globais um trabalho das instituições voltado para um público mais diversificado, através de formas de trabalho promotoras de uma maior interação com os seus diversos tipos de visitantes. Para isso, segundo os posicionamentos da Nova Museologia, o museu deve reposicionar-se, através:

I. da discussão sobre a natureza da instituição, a sua missão e lugar na sociedade, podendo emergir como lugar central para a discussão dos grandes temas da contemporaneidade (Duarte, 2013), num formato de trabalho promotor da humanização, com a representação dos diversos indivíduos e subgrupos sociais através de uma museologia participativa (Silverman, 2010) ${ }^{9}$;

entre a ciência e a tecnologia com outras modalidades de reconstituição, interpretação e intervenção na realidade que não alienem as dimensões sociais da mesma.

${ }^{7}$ Entre a década de 30 e a de 60 do séc. XX, a museologia tradicional continuou a prevalecer em regimes com elevados níveis de instrumentalização político-ideológica, como os regimes liberais conservadores, monarquias autocráticas e ditaduras autoritárias ou totalitárias. Por outro lado, a Nova Museologia e a nova noção alargada de património cultural correspondem a regimes democráticos ou democracias liberais avançadas, sistemas políticos mais abertos que aceitam o pluralismo cultural e ideológico (Nunes, 2010; Bennett, 1995).

8 "O museu é uma instituição permanente sem fins lucrativos, ao serviço da sociedade e do seu desenvolvimento, aberta ao público, que adquire, conserva, investiga, comunica e expõe o património material e imaterial da humanidade e do seu meio envolvente com fins de educação, estudo e deleite." (ICOM, 2015)

9 Porém, não podemos deixar de sublinhar o atraso desta exposição em relação às suas congéneres europeias, onde já em princípios do século XX, no âmbito dos movimentos cubista e dadaísta, este tipo de cruzamentos era frequente 
Pereira, Sérgio (2020). Discursos expositivos enquanto recurso pedagógico: análise de uma experiência escolar desenvolvida entre 2006 e 2017. In Alice Duarte (ed.), Seminários DEP/FLUP vol. 1. Porto: Universidade do Porto, Faculdade de Letras/DCTP, p. 118-140. https://doi.org/10.21747/9789898969682/seminariosv1a6

II. da aposta em discursos expositivos capazes de ilustrar e representar de forma simplificada visões complexas da realidade, criando conexões entre esta e os conteúdos das exposições apresentadas (Allard e Bouché, 1998);

III. da capacidade para a apresentação de conteúdos através de novas técnicas museográficas desenvolvidas pela museologia e pela museografia, sobretudo em exposições temporárias que apostem no recurso a suportes não tradicionais (com algum destaque para a multimédia), capazes de atrair e renovar os públicos (Nunes, 2010);

IV. do reforço do seu papel educativo, com o desenvolvimento de atividades que reforcem a ligação ao público escolar, permitindo ao museu sobressair enquanto complemento importante ao ensino formal escolar, espaço de auxílio à compreensão, validação e expansão de horizontes acerca de conhecimentos adquiridos no sistema educativo. O serviço educativo da instituição deverá ser capaz de, no âmbito de uma situação pedagógica, propor um programa educativo adequado, através de diferentes estratégias didáticas (Allard e Boucher, 1998);

V. no reconhecimento da importância da experiência participativa que pode ser oferecida pelo museu: exposições capazes de colocar o visitante, não apenas no papel de espectador passivo, passando a dar-lhe a oportunidade para criar, partilhar e conectar-se com outros visitantes em torno do seu conteúdo (Simon, 2010);

VI. no reconhecimento da investigação científica, não apenas fulcral para a descoberta e verificação das peças expostas, mas também para auxiliar o desenvolvimento de informação sobre contextos expostos (Nunes, 2010); nesta linha, os espaços complementares dos museus (bibliotecas, centros de documentação e arquivos) podem ser potenciados e podem criar novas dinâmicas de trabalho com o contexto educativo, expandindo as áreas de visita para lá das salas expositivas;

VII. da desconstrução da dita cultura erudita, através de uma atividade museológica capaz de contribuir para a transformação do público que deve ser entendido como plural e diverso (Macdonnald, 2006), com essa 
Pereira, Sérgio (2020). Discursos expositivos enquanto recurso pedagógico: análise de uma experiência escolar desenvolvida entre 2006 e 2017. In Alice Duarte (ed.), Seminários DEP/FLUP vol. 1. Porto: Universidade do Porto, Faculdade de Letras/DCTP, p. 118-140. https://doi.org/10.21747/9789898969682/seminariosv1a6

democratização do acesso à cultura a ser trabalhada desde logo com o público escolar;

VIII. maior ligação com a comunidade envolvente e afirmação do papel do museu enquanto pilar do desenvolvimento comunitário, com a implicação dos cidadãos na sua autorrepresentação, para desenvolverem o sentimento de utentes prioritários detentores do património cultural; esta perspetiva do museu enquanto "zona de contacto" (Clifford, 1997; Witcomb, 2003) também se aplica ao público escolar, que aqui pode encontrar um espaço privilegiado de interação entre alunos e outros intervenientes socioculturais para além da comunidade educativa.

Em suma, de forma transversal, o museu vai-se transformando nos diferentes períodos históricos e em diversos contextos socioculturais num espaço para afirmação de diversas formas de pensar, para o realçar de identidades individuais e coletivas e para o registo de dimensões artísticas, científicas e sociais. Porém, a ação da instituição museológica não deixa de estar condicionada pelo contexto social e político no qual se insere. Ainda assim, de forma mais ou menos condicionada, no tempo presente o fundamento de qualquer museu parece surgir cada vez mais centrado na apresentação de conteúdos expositivos em diferentes formatos, mas com um objetivo comum: a difusão de informação para o conhecimento e a consciencialização cívica (o que também é aumento do nível educativo) dos seus usuários.

\section{Contextualização do ambiente escolar}

O Colégio Internato dos Carvalhos, onde fui docente entre 2006 e 2018, fica situado em Pedroso, Vila Nova de Gaia, a cerca de $10 \mathrm{~km}$ do Porto. Trata-se de uma instituição de ensino privada centenária, sob alçada da ordem religiosa dos Missionários Claretianos. Este Colégio também se distingue pelo percurso já histórico de inovação no ensino que o coloca numa posição de destaque na oferta escolar da região norte, ainda hoje pela oferta de cursos com planos curriculares próprios, ao nível do ensino secundário. Estes cursos, definidos como cursos cientifico-tecnológicos, possibilitam aos 
Pereira, Sérgio (2020). Discursos expositivos enquanto recurso pedagógico: análise de uma experiência escolar desenvolvida entre 2006 e 2017. In Alice Duarte (ed.), Seminários DEP/FLUP vol. 1. Porto: Universidade do Porto, Faculdade de Letras/DCTP, p. 118-140. https://doi.org/10.21747/9789898969682/seminariosv1a6

estudantes uma forte formação de carácter profissionalizante sem fechar portas à possibilidade de continuidade de estudos a um nível superior.

Apesar de privado, é um Colégio que aglutina estudantes de realidades diversas já que o ensino é pago pelas famílias até ao 9ano, mas é gratuito no nível secundário. Assim sendo, numa mesma turma do ensino secundário podem coabitar estudantes de proveniência geográfica e de perfil económico e cultural distintos ${ }^{10}$.

As atividades aqui em análise foram enquadradas nos conteúdos curriculares da disciplina bianual (11ㅇ e $12^{\circ}$ s anos) de Património e Museus, do curso cientificotecnológico em Património e Turismo. Trata-se de uma disciplina com objetivos em torno do estudo dos museus, procurando incutir nos estudantes competências profissionais para intervenções em torno do património museológico enquanto elemento de relevância cultural, bem como a promoção, valorização e integração desse património em atividades turísticas.

\section{Atividades pedagógicas de caráter expositivo}

As atividades desenvolvidas no âmbito da disciplina de Património e Museus eram de carácter pedagógico. Porém, eram também optativas, surgidas das minhas iniciativas enquanto docente. A disciplina incluía conteúdos programáticos diversos, como o estudo da relação do museu com a sociedade (papel social e interdisciplinaridade), a gestão de museus, a conservação de coleções e as práticas de informação e animação em espaços museológicos. O processo de ensino/aprendizagem destes conteúdos foi desafiante, pois, se havia conteúdos curriculares mais fáceis de ensinar dentro da sala de aula, outros levavam sistematicamente à mesma questão: como ensinar as práticas de informação e animação em espaços museológicos permanecendo no espaço físico de uma escola? Foi neste sentido que a procura de formas de aprendizagem mais dinâmicas surgiu, enquanto processo natural e intuitivo, que neste ponto procuro esclarecer.

\footnotetext{
${ }^{10}$ Estudantes do contexto geográfico da escola e estudantes deslocados, de outras regiões nacionais e do estrangeiro. Alguns estudantes estudam no Colégio desde o ensino básico (ensino de lecionação paga) e outros apenas no secundário para frequência dos cursos profissionais (ensino financiado). Os estudantes deslocados suportam o custo do regime de internato.
} 
Pereira, Sérgio (2020). Discursos expositivos enquanto recurso pedagógico: análise de uma experiência escolar desenvolvida entre 2006 e 2017. In Alice Duarte (ed.), Seminários DEP/FLUP vol. 1. Porto: Universidade do Porto, Faculdade de Letras/DCTP, p. 118-140. https://doi.org/10.21747/9789898969682/seminariosv1a6

Assim, as atividades desenvolvidas em torno dos discursos expositivos foram de diferentes tipologias. Inicialmente, comecei por promover visitas de estudo a museus e a outros espaços museológicos, locais aos quais associamos a componente expositiva enquanto característica intrínseca dos mesmos. São igualmente espaços de forte componente educativa, com ações de educação não-formal desenvolvidas sobretudo para o público escolar. Entre 2006 e 2017 foram 17 os museus visitados ${ }^{11}$, em formato de visita livre ou em formato de visita guiada ${ }^{12}$.

As visitas de estudo a museus são uma das formas mais tradicionais de um professor procurar motivar os seus discentes para os conteúdos programáticos, nas mais vastas áreas de ensino. Esta aposta recorrente dos professores no recurso à visita museal é um reflexo do seu entendimento enquanto espaço de ensino não-formal, muitas vezes capaz de proporcionar representações simplificadas da realidade (Allard e Boucher, 1998), em prol de se desenvolverem, enriquecerem, verificarem e modificarem os conhecimentos adquiridos no sistema formal de ensino. Por outro lado, a oferta de programas educativos em museus adequados aos conteúdos curriculares escolares tem crescido e parece fazer jus à própria definição de museu proposta pelo ICOM que destaca o papel educativo destas instituições. Na minha experiência enquanto docente, a realização das visitas de estudo era positiva, porém com limitações relativamente ao cumprimento dos conteúdos programáticos da disciplina de Património e Museus. Estas visitas eram atividades fornecidas pelos serviços educativos dos museus, orientadas para a aquisição de saberes sobre a cultura, as artes e a sociedade; eram feitas através da comunicação entre o objeto exposto, o mediador e os estudantes. Nestas, o mediador (guia da visita) tinha sempre um papel determinante, na medida em que para os estudantes a experiência no museu passava essencialmente pela receção da informação por ele produzida e pela posterior observação, condicionada

\footnotetext{
11 Museus visitados em visitas de estudo entre 2006 e 2018: Museu da Citânia de Sanfins (Paços de Ferreira, out. 2007), Museu Coleção Berardo (Lisboa, jan. 2008), Museu Nacional do Teatro (Lisboa, jan. 2009), Museu Nacional do Traje e da Moda (Lisboa, jan. 2009), Museu do Oriente (Lisboa, jan. 2010), Caves e Museu Ramos Pinto (Vila Nova de Gaia, out. 2001 e jan. 2015), Museu Nacional dos Coches (Lisboa, fev. 2011), Museu Nacional do Design e da Moda (Lisboa, fev. 2011), Museu de Serralves (Porto, out. 2010, fev. 2012, out. 2012, out. 2014 e nov. 2016), Museu Nacional Rainha Sofia (fev. 2013 e fev. 2015), Caixa Fórum Madrid (fev. 2013).

12 Nalguns museus, particularmente o Museu de Serralves, as visitas foram regulares pela proximidade geográfica, pela eficiência no agendamento das visitas e pela vasta oferta de atividades do serviço educativo.
} 
Pereira, Sérgio (2020). Discursos expositivos enquanto recurso pedagógico: análise de uma experiência escolar desenvolvida entre 2006 e 2017. In Alice Duarte (ed.), Seminários DEP/FLUP vol. 1. Porto: Universidade do Porto, Faculdade de Letras/DCTP, p. 118-140. https://doi.org/10.21747/9789898969682/seminariosv1a6

por essa informação pré-fornecida. Sendo o discurso expositivo em si próprio um ato de mediação e comunicação, esta, neste contexto de visitas, é sempre condicionada, não tendo os estudantes um poder de interpretação direto sob o material ou assunto exposto. Por outro lado, por mais informada que a instituição estivesse da área de estudo dos estudantes em visita e das necessidades destes, os modelos de visitas oferecidos eram sistematicamente centrados num discurso em torno da importância do museu visitado enquanto instituição, da exposição enquanto produto finalizado e das obras e artistas nela representados. Estas visitas não davam, portanto, resposta a parte do meu desafio, relacionado com a preparação de futuros estagiários ou trabalhadores em museus, através da aprendizagem sobre as práticas de trabalho desenvolvidas em

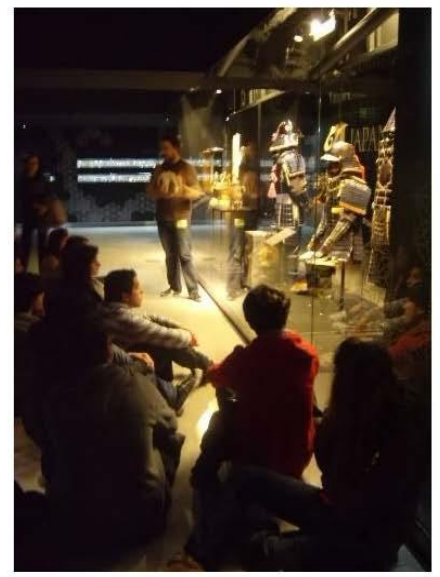

Fig. 1-Visita ao Museu do Oriente nov. 2010

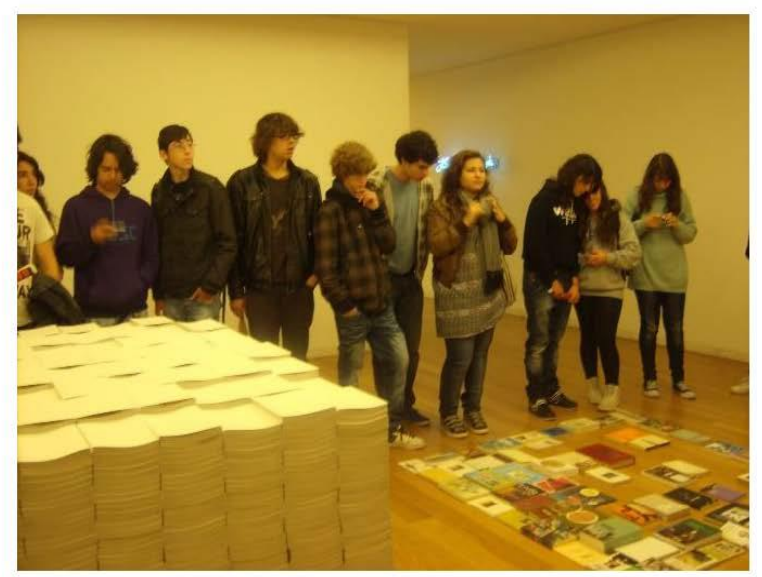

Fig. 2-Visita ao Museu de Serralves nov. 2010

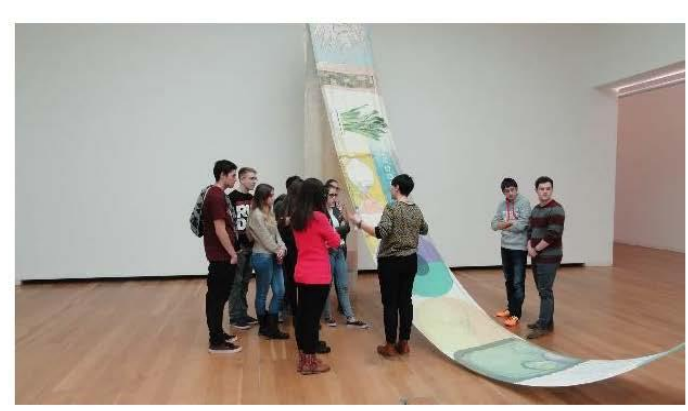

Fig. 3-Visita ao Museu de Serralves out. 2014

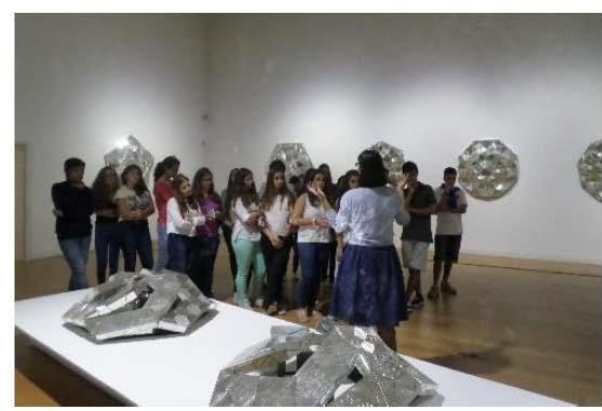

Fig. 4-Visita ao Museu de Serralves out. 2015

contexto museológico, que possibilitassem a apresentação de exposições, entre outras atividades.

Cheguei assim à conclusão de que quando o próprio museu e os seus processos de trabalho são a área de ensino, apenas existem programas educativos direcionados 
Pereira, Sérgio (2020). Discursos expositivos enquanto recurso pedagógico: análise de uma experiência escolar desenvolvida entre 2006 e 2017. In Alice Duarte (ed.), Seminários DEP/FLUP vol. 1. Porto: Universidade do Porto, Faculdade de Letras/DCTP, p. 118-140. https://doi.org/10.21747/9789898969682/seminariosv1a6

aos estudantes do ensino superior, particularmente da área da museologia e da museografia. Por outro lado, à medida que fui realizando as visitas de estudo atrás descritas percebi também que a vivência da experiência museal ficava limitada no tempo e no espaço, tornando o estudante em mero espectador de uma ação finalizada, apresentada e que terminava no final da visita. Neste contexto, procurei formas que possibilitassem aos estudantes a participação ativa na criação de atividades de caráter expositivo, ultrapassando a lógica do estudante observador e incluindo uma dimensão de estudante-participante no processo.

Estas formas procuraram dar resposta a dois problemas fundamentais. $\mathrm{O}$ primeiro, relativo aos constrangimentos na escola, relacionados com a não existência na mesma de um espaço físico de características museológicas. O segundo, cruzado com o tipo de visitas oferecidas nos museus, demasiado centradas nas exposições finais e obras apresentadas, pouco permissivas no sentido de permitirem o entendimento dos processos, do trabalho técnico dos bastidores, o que as fazia não responderem por completo às necessidades da disciplina. Neste sentido, progressivamente fui complementando as visitas com o desenvolvimento de projetos pedagógicos de maior duração e com a realização de exposições no espaço escolar. Estas atividades foram enquadradas nos conteúdos curriculares e eram consideradas um contributo para o desenvolvimento de uma avaliação à disciplina mais focada na componente prática.

Relativamente aos projetos pedagógicos, estes foram desenvolvidos em contexto de sala de aula. Consistiam na elaboração prática de trabalhos em torno de temáticas específicas, centradas em assuntos e não em objetos, complementando visitas de estudo previamente efetuadas. Neste âmbito destaco três projetos. A Minha Escola Adota um Museu (2007), um projeto de cooperação anual com o Museu Nacional de Soares dos Reis onde, através de várias experiências de campo, os estudantes se exercitavam no desempenho do papel de guias do museu durante um dia. Esta atividade deu origem a um documentário em vídeo (figura 5). 
Pereira, Sérgio (2020). Discursos expositivos enquanto recurso pedagógico: análise de uma experiência escolar desenvolvida entre 2006 e 2017. In Alice Duarte (ed.), Seminários DEP/FLUP vol. 1. Porto: Universidade do Porto, Faculdade de Letras/DCTP, p. 118-140. https://doi.org/10.21747/9789898969682/seminariosv1a6

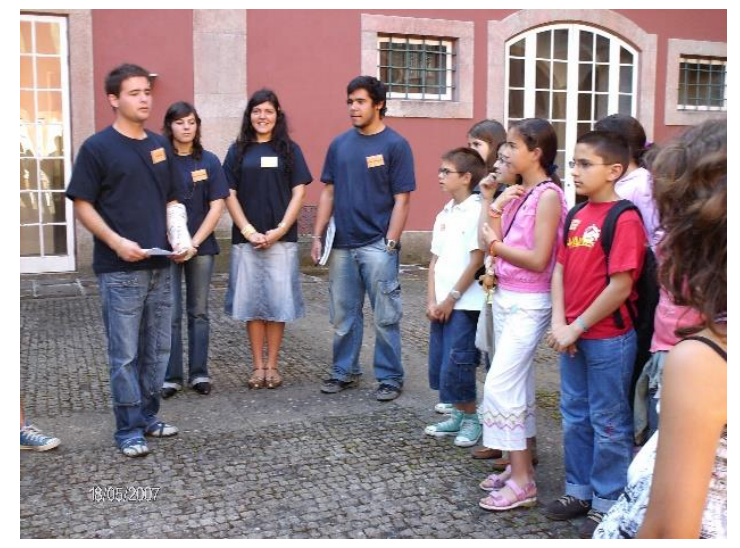

Fig. 5-Projeto com o Museu Nacional Soares dos Reis

O Museu Vai à Escola (2007), projeto anual com a Casa Museu Teixeira Lopes, com visitas de estudo ao museu, um workshop na escola orientado pelo serviço educativo da instituição museológica e uma exposição para divulgação do património do museu junto da comunidade educativa. A alquimia da Cor (2011) foi o mais complexo dos três projetos, por ser pluridisciplinar, englobando três cursos da escola nas áreas da química, artes e turismo. Ao longo da sua realização foram feitas visitas de estudo e aulas interdisciplinares entre os cursos. Enquanto objetivo global, a atividade visou criar uma consciência cívica sobre a importância da preservação da biodiversidade pela divulgação de espécies protegidas, em paralelo com a importância da preservação do património artístico de pinturas murais e a fresco (figuras 6 e 7).

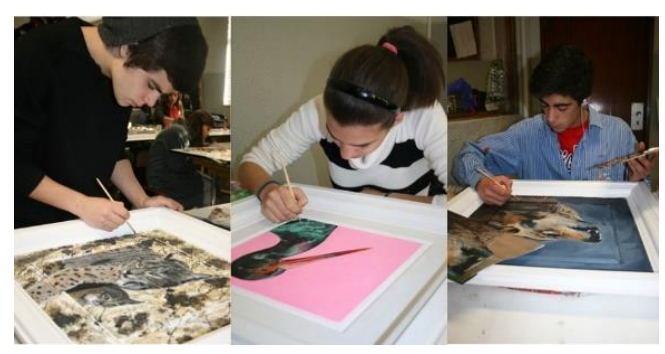

Fig. 6-Projeto Alkimya da Cor

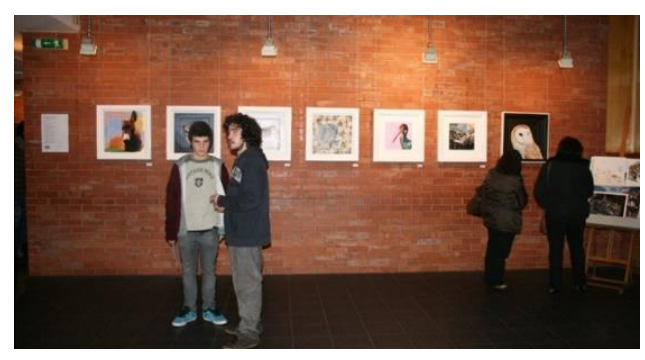

Fig. 7-Projeto Alkimya da Cor

Dito de forma simples, este projeto culminou com a montagem de uma exposição de pintura, com obras realizadas pelos estudantes de artes, pintadas através dos pigmentos naturais preparados pelos estudantes de química e com a representação de espécies animais em risco no nosso país, identificadas no roteiro de património natural, criado pelos estudantes de turismo. 
Pereira, Sérgio (2020). Discursos expositivos enquanto recurso pedagógico: análise de uma experiência escolar desenvolvida entre 2006 e 2017. In Alice Duarte (ed.), Seminários DEP/FLUP vol. 1. Porto: Universidade do Porto, Faculdade de Letras/DCTP, p. 118-140. https://doi.org/10.21747/9789898969682/seminariosv1a6

Quanto às exposições na escola, elas permitiam aos estudantes a aplicação de conhecimentos teóricos relativos às técnicas de criação e gestão de exposições, com a implementação de técnicas de ensino não-formais. Estas exposições foram apresentadas na galeria-bar, espaço de lazer e convívio para toda a comunidade educativa, e tiveram temáticas diversas. Por exemplo a arte cinematográfica, com a exposição Rostos do Cinema (2011), mostra fotográfica e documental, desenvolvida para celebração do 60ำ Festival de Cinema de Cannes, apresentava imagens de rostos marcantes de alguns filmes estreados no Festival, bem como os cartazes promocionais dos filmes premiados com a Palma de Ouro nos dez últimos anos (figura 8).

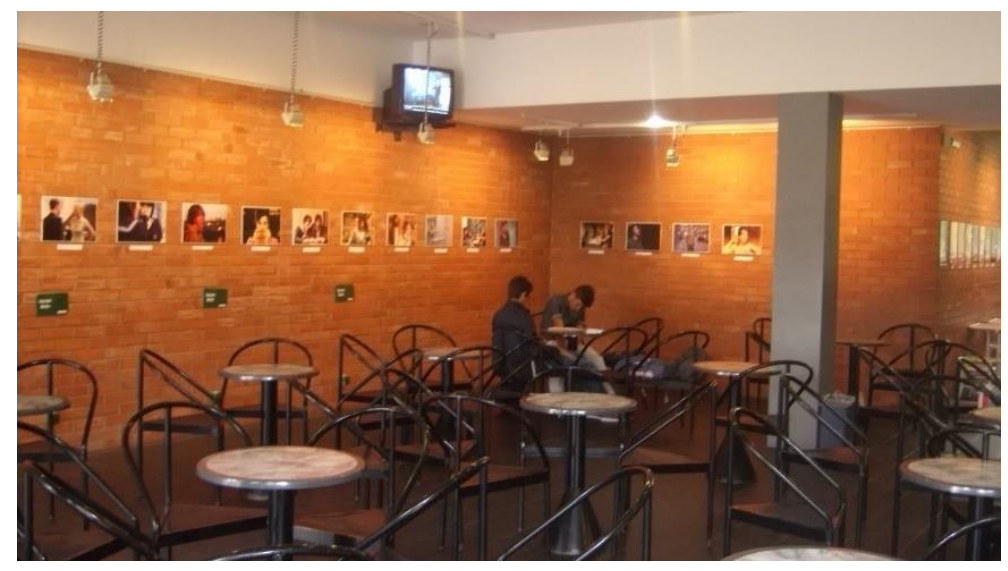

Fig. 8-Exposição Rostos do Cinema (2011)

Algumas exposições focavam diretamente os destinos turísticos, como a exposição fotográfica Onde Vamos em 2012?, que apresentou imagens dos destinos turísticos em destaque pela imprensa mundial nesse ano. Orientei também duas exposições enquadradas no Dia Mundial do Turismo, em 2013 e 2014. Neste caso, foram exibidos em formato impresso posters oficiais da Organização Mundial do Turismo criados para divulgação da data, bem como imagens alusivas a destinos de viagens enquadrados nas temáticas escolhidas pela organização em cada um dos anos ${ }^{13}$. Finalmente a exposição Imaginário de Sons (2015), sobre o trabalho desenvolvido na oficina educativa Imaginário de Sons na qual os estudantes participaram no Museu de Serralves. Neste caso, deixou de ser apenas uma atividade de um grupo escolar levada a cabo no espaço do museu, para ganhar também um sentido inverso, onde o trabalho

\footnotetext{
${ }^{13}$ Tema do Dia Mundial do Turismo: Turismo e Água - Proteger o Nosso Futuro Comum (2013), Turismo e Desenvolvimento Comunitário (2014).
} 
Pereira, Sérgio (2020). Discursos expositivos enquanto recurso pedagógico: análise de uma experiência escolar desenvolvida entre 2006 e 2017. In Alice Duarte (ed.), Seminários DEP/FLUP vol. 1. Porto: Universidade do Porto, Faculdade de Letras/DCTP, p. 118-140. https://doi.org/10.21747/9789898969682/seminariosv1a6

elaborado no museu foi levado e retrabalhado no espaço da escola, materializando assim uma outra dimensão da Nova Museologia pelo que permitiu de chamada de questões que tiveram efeitos também fora do museu. A exposição apresentou os trabalhos de desenho e pintura feitos pelos estudantes na oficina de artes e documentou o processo da própria oficina através de fotografia, tendo sido uma oportunidade para dar continuidade à atividade fora da sala educativa do museu (figura 9).

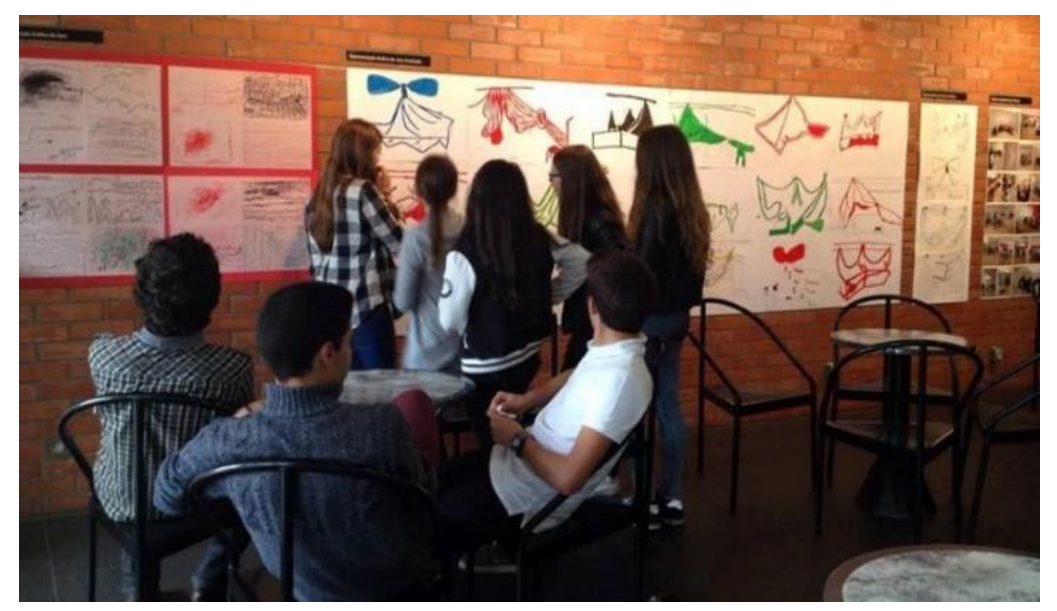

Fig. 9-Exposição Imaginário de Sons

Em termos de exposições, destaco também a preparação anual dos trabalhos a expor no Stand do Curso de Património e Turismo, enquadrados num espaço expositivo da Semana Aberta da escola, dedicada à apresentação da sua oferta educativa e complementada com eventos culturais. O planeamento, preparação de materiais e montagem do Stand era feito dentro do período das aulas, sendo uma verdadeira oportunidade para desenvolver com os estudantes uma experiência expositiva de raiz. Após a definição de uma temática ${ }^{14}$, era concebida a ideia para o espaço, a sua idealização em maquete e a preparação dos materiais a expor: vídeos para projeção, instalações sonoras, pintura de posters e murais, construção de objetos e recolha de outros, cartazes informativos, atividades performativas, entre outras (figuras 10 e 11).

\footnotetext{
${ }^{14}$ Tema dos Stands do Curso de Património e Turismo na EXPOCIC, entre 2009 e 2018: Interrrail (2009); Os cafés, espaços históricos e culturais (2010); O turismo responsável (2011); Guimarães, Capital Europeia da Cultura (2012); Porto, Destino Europeu do ano (2014); Turismo Étnico (2015); Paisagens Globais: Destinos Icónicos no Mundo (2016); Viajar de avião (2017).
} 
Pereira, Sérgio (2020). Discursos expositivos enquanto recurso pedagógico: análise de uma experiência escolar desenvolvida entre 2006 e 2017. In Alice Duarte (ed.), Seminários DEP/FLUP vol. 1. Porto: Universidade do Porto, Faculdade de Letras/DCTP, p. 118-140. https://doi.org/10.21747/9789898969682/seminariosv1a6

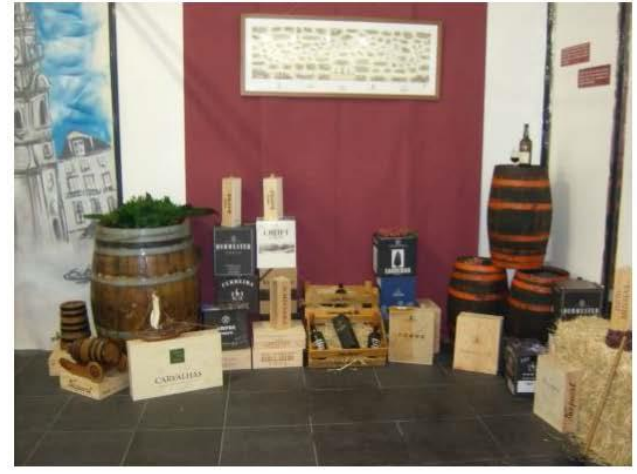

Fig. 10 Stand do Curso de Património e Turismo 2014/ Fonte: Sérgio Pereira

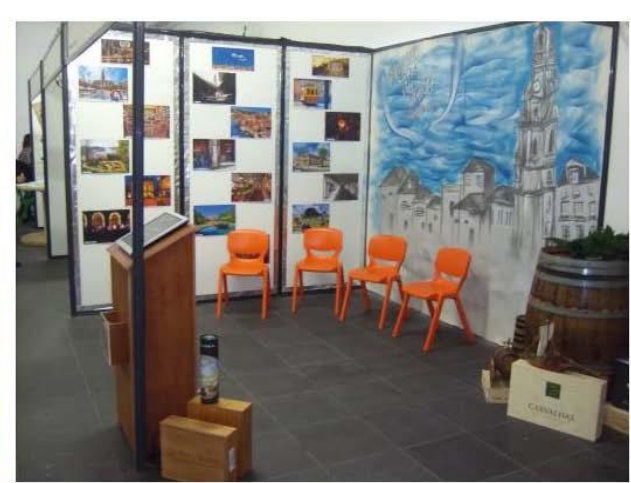

Fig. 11 Stand do Curso de Património e Turismo, 2015 Fonte: Sérgio Pereira

Em suma, a realização de visitas de estudo passou a ser um meio para o desenvolvimento de projetos pedagógicos mais amplos centrados em atividades expositivas, deixando estas de ser experiências com um término em si mesmas.

\section{Dificuldades do processo desenvolvido}

A disciplina de Património e Museus pressupunha um regime de ensino teóricoprático, porém, a existência nesta disciplina de uma conduta educativa verdadeiramente prática dependeu de diversos fatores. À medida que me fui desprendendo de um sistema de aulas teóricas para procurar formas de aprendizagem mais dinâmicas surgiam outras dificuldades. Estas estavam relacionadas com: a) o contexto escolar em concreto, b) o seu enquadramento sociogeográfico e c) a forma de funcionamento dos serviços educativos nos museus contactados. Como referido no ponto anterior, o processo aqui retratado resultou da procura de soluções para dois desafios fundamentais: tornar os métodos de ensino menos formais durante a minha atividade letiva e colmatar as próprias limitações das atividades de ensino não-formal disponibilizadas pelos museus.

Efetivamente, foquei-me no meu campo de ação (a escola) para criar um sistema de ensino menos formal, recorrendo ao desenvolvimento de atividades práticas dentro do período de aulas da disciplina. Estas atividades recorreram assim a estratégias da Nova Museologia, cujos fundamentos e desenvolvimentos podem também ser úteis quando aplicados nas questões educativas, mesmo fora do museu. Todavia, à medida que fui apostando na implementação dessas novas estratégias, foram sendo 
Pereira, Sérgio (2020). Discursos expositivos enquanto recurso pedagógico: análise de uma experiência escolar desenvolvida entre 2006 e 2017. In Alice Duarte (ed.), Seminários DEP/FLUP vol. 1. Porto: Universidade do Porto, Faculdade de Letras/DCTP, p. 118-140. https://doi.org/10.21747/9789898969682/seminariosv1a6

identificadas as referidas dificuldades, numa primeira fase relacionadas, sobretudo, com as dinâmicas próprias do espaço escolar. Desde logo, sendo uma escola um espaço altamente normativo, ações que extrapolam o espaço físico da sala de aula não eram fáceis de implementar ${ }^{15}$. Por outro lado, o número de visitas a museus ao longo de um ano letivo teve de ser limitado pelas implicações que causavam nas dinâmicas de ensino ${ }^{16}$. Ainda sobre o contexto escolar, deve ser referido o cariz religioso da escola em causa, da qual dependia o delinear e validar dos discursos a serem desenvolvidos nas atividades expositivas que iam sendo desenvolvidas ${ }^{17}$. Também o contexto sociogeográfico da escola afetou este processo, devido ao agravamento do contexto económico da comunidade envolvente, verificando-se: a não participação de estudantes suficientes nalgumas visitas levou ao cancelamento de algumas atividades em museus; a redução da disponibilidade das famílias dos estudantes para financiarem visitas de estudo e oficinas educativas ${ }^{18}$; o aumento do valor cobrado às escolas pelas instituições museológicas, bem como dos preços de locomoção cobrados pelas companhias de transportes.

Contextualizadas as dificuldades relacionadas com o funcionamento do estabelecimento de ensino e com o perfil dos estudantes, interessa agora abordar de forma mais consistente a outra vertente, relativa aos resultados dos contactos com os museus. De facto, o funcionamento dos serviços educativos dos museus contactados revelou-se também uma dificuldade, sobretudo pelas implicações para os estudantes, aquando da concretização das visitas, em termos da deslocação e do custo de participação no museu, colocando desde logo em discussão a forma de funcionamento

\footnotetext{
${ }^{15} \mathrm{Na}$ prática, não eram bem vistas e eram, por vezes, dificultadas, pois para a gestão escolar é menos problemático ter estudantes controlados numa sala de aula do que a agir em outros espaços escolares. A não valorização das atividades fora da sala de aula foi um fator de desmotivação traduzido na não concretização de outras atividades inicialmente pensadas.

${ }^{16}$ Uma visita realizada com uma turma, implica a falta do professor à lecionação de outras turmas não participantes na visita; ou a falta dos estudantes às aulas de outras disciplinas.

17 Sendo uma escola de matriz religiosa, católica, sentiram-se muitas vezes entraves à elaboração de exposições e outras atividades. Houve alguma relutância à utilização do espaço escolar para outras atividades, já que a escola estava apenas habituada a ver exposições desenvolvidas pelos estudantes do curso de Artes, para apresentação dos seus trabalhos. Tirando estas, apenas parecia ser possível expor materiais enquadráveis nas mensagens católicas da escola, patrocinados pelos ateliês ou pelo gabinete de orientação vocacional.

${ }^{18}$ Grande parte dos estudantes eram provenientes dos concelhos de Vila Nova de Gaia, Feira e Espinho, e a crise financeira pós 2008 levou ao desemprego de muitas famílias, sobretudo nestes dois últimos concelhos.
} 
Pereira, Sérgio (2020). Discursos expositivos enquanto recurso pedagógico: análise de uma experiência escolar desenvolvida entre 2006 e 2017. In Alice Duarte (ed.), Seminários DEP/FLUP vol. 1. Porto: Universidade do Porto, Faculdade de Letras/DCTP, p. 118-140. https://doi.org/10.21747/9789898969682/seminariosv1a6

destes serviços. Efetivamente, os museus apostam num modelo de trabalho centrado na deslocação dos estudantes aos espaços físicos dos mesmos, havendo uma falta de disponibilidade dos museus para o desenvolvimento de atividades em espaços escolares. Isto põe em causa a concretização de uma ligação forte à comunidade envolvente e à democratização do acesso à cultura perspetivadas pela Nova Museologia. Nos museus contactados, os procedimentos são uniformizados. Sugere-se uma alteração para novos modelos, em que a experiência do museu pudesse começar, ter etapas ou terminar na escola, por exemplo, com a deslocação das equipas do museu até esta. Tendencialmente, para os estudantes, a ideia de ir a um museu significa a entrada num espaço de distanciamento físico e emocional. Esta questão poderia ser trabalhada através de uma ligação, fomentada por um melhor entendimento dos diferentes públicos do museu e das necessidades destes - neste caso, dos diferentes tipos de públicos escolares, no sentido de tornar a experiência mais participativa (Simon; 2010).

A forma de funcionamento dos museus contactados nestas experiências parece não colocar em prática perspetivas que fomentem a criação de atividades promotoras de uma maior participação dos públicos escolares no contexto museológico. O público escolar é o maior frequentador de museus e, tal facto, justificaria a existência de uma maior atenção às necessidades educativas deste público, muitas vezes menosprezado face a outros públicos dos museus. A educação nos museus é geralmente considerada não-formal, por oposição ao ensino oficial. Porém, pude verificar, muitas vezes, que as atividades disponibilizadas para grupos escolares são conduzidas por educadores com um discurso maioritariamente expositivo e teórico. Os estudantes poucas vezes têm oportunidade de ver, observar, contemplar e manipular, ficando sobretudo a ouvir o discurso do educador que se sobrepõe fisicamente ao material exposto (Ascenção, 2012). Os estudantes devem ser entendidos como partes de um público diverso, plural e ativo, não sendo uma massa homogênea e passiva (Sharon Macdonald, 2006). Se falarmos em oficinas educativas, estas estão também focadas no desenvolvimento de atividades orientadas para temáticas em torno da coleção dos museus ou dos seus valores institucionais, numa lógica em que o museu define um "menu" preparado de programas à escolha, com discursos formatados para visitas guiadas e oficinas 
Pereira, Sérgio (2020). Discursos expositivos enquanto recurso pedagógico: análise de uma experiência escolar desenvolvida entre 2006 e 2017. In Alice Duarte (ed.), Seminários DEP/FLUP vol. 1. Porto: Universidade do Porto, Faculdade de Letras/DCTP, p. 118-140. https://doi.org/10.21747/9789898969682/seminariosv1a6

temáticas. Esta forma de operar pré-formatada condiciona o tipo de abordagens à narrativa expositiva, limitando a discussão de tópicos com interesse social, político ou ideológico, que poderiam ir ao encontro das necessidades do público escolar. Por outro lado, relativamente às experiências aqui expostas, raramente o museu se coloca enquanto tema de trabalho, para ver o seu espaço entendido, interpretado e retrabalhado pelo público escolar. Apesar de solicitado várias vezes, raramente foi oferecido um programa educativo em que o próprio museu se apresentasse como tema numa visão alargada, incluindo também o acesso aos seus métodos de trabalho e aos seus bastidores, de forma a dar resposta às necessidades do programa curricular que se procurava lecionar.

Certamente que o funcionamento do serviço educativo dos museus se ressente de um percurso histórico em Portugal que só muito lentamente veio dar relevância aos seus profissionais. Só tardiamente surgiram os cursos universitários para a formação de profissionais dos serviços educativos, sendo que esses cursos iniciais visavam predominantemente formar futuros conservadores, restauradores, curadores e investigadores. Sendo uma profissão que carece de reconhecimento, torna-se muitas vezes precária, praticada por profissionais chamados apenas quando necessários e pagos com recibos verdes, ou efetuada por funcionários de empresas independentes num regime de outsourcing, o que em nada promove a integração do serviço educativo na respetiva instituição museológica (Ascenção, 2012).

Por fim, atentando na visão do museu enquanto espaço integrador, de construção e comunicação de valores e identidades, de "zona de contacto" para as comunidades, ao serviço do desenvolvimento comunitário (Clifford, 1997; Witcomb, 2003), esta filosofia parece não estar a ser aplicada à forma de trabalho face aos grupos escolares. Realizadas no formato de atividades orientadas para uma escola, os museus não promovem o contacto entre estudantes de outras escolas ou demais públicos. As atividades padronizadas encontradas apenas permitem o contacto com os guias do museu e com os técnicos do serviço educativo, num sistema bastante formal de trabalho em que parece que o professor é momentaneamente substituído por outra figura que assume o discurso e decorrentes tarefas. 
Pereira, Sérgio (2020). Discursos expositivos enquanto recurso pedagógico: análise de uma experiência escolar desenvolvida entre 2006 e 2017. In Alice Duarte (ed.), Seminários DEP/FLUP vol. 1. Porto: Universidade do Porto, Faculdade de Letras/DCTP, p. 118-140. https://doi.org/10.21747/9789898969682/seminariosv1a6

\section{Contributos do processo desenvolvido}

Em termos de aspetos positivos, as atividades desenvolvidas foram, de um ponto de vista pessoal, úteis sob diversos pontos de vista. Desde logo, foram um contributo para o processo de ensino-aprendizagem em vários quadrantes. Primeiro, por me terem permitido diversificar os métodos de avaliação relativos à disciplina, em termos qualitativos e quantitativos ${ }^{19}$. Segundo, possibilitaram consolidar a vertente prática inerente à disciplina. Com a preparação de exposições temáticas na escola e com a montagem anual do Stand do curso foi possível efetivamente criar atividades práticas em contexto de sala de aula e incluir a atividade expositiva enquanto componente de exercício das aulas, através da conceção e montagem das exposições. Terceiro, impulsionou a motivação dos estudantes em relação aos conteúdos programáticos. Todos os anos letivos havia uma resistência por parte dos estudantes, que olhavam para os museus como espaços aborrecidos e antiquados. Assim, através das visitas de estudo e da participação em oficinas educativas, procurava-se motivar os estudantes para as temáticas em estudo. Foi interessante verificar que, mais tarde, os próprios estudantes foram desenvolvendo pequenas exposições temáticas por iniciativa própria, enquadradas nos seus Projetos Tecnológicos e Estágio (PTE'S), componente curricular obrigatória para conclusão do 12ㅇano.

Por outro lado, esta forma de trabalho que foi sendo desenvolvida em torno da disciplina foi certamente um contributo para a descoberta de novas competências nos estudantes. Tendencialmente estes entravam no curso focados na hotelaria e nos transportes enquanto áreas profissionais futuras, descurando a possibilidade de seguir carreia em áreas de âmbito mais cultural ligadas ao trabalho em espaços patrimoniais e

\footnotetext{
${ }^{19}$ Em termos de avaliação qualitativa, as atividades em museus eram revistas e discutidas em contexto de sala de aula, com recurso à projeção das imagens resultantes do registo fotográfico. Também se procedia ao preenchimento de um questionário de avaliação da atividade. Quer o questionário quer a discussão incidiam sobre tópicos como: o espaço físico do museu, as exposições, o trabalho desenvolvido nas oficinas e a performance dos funcionários. Assim, era possível avaliar a apreensão global de conhecimentos por parte dos estudantes, bem como identificar pontos positivos e negativos identificados pelos discentes relativos à atividade realizada. Em termos quantitativos, as atividades efetuadas em correlação com os conteúdos programáticos eram abordadas em contexto de avaliação sumativa - por exemplo, eram objeto de questões nos testes de avaliação.
} 
Pereira, Sérgio (2020). Discursos expositivos enquanto recurso pedagógico: análise de uma experiência escolar desenvolvida entre 2006 e 2017. In Alice Duarte (ed.), Seminários DEP/FLUP vol. 1. Porto: Universidade do Porto, Faculdade de Letras/DCTP, p. 118-140. https://doi.org/10.21747/9789898969682/seminariosv1a6

museológicos. Progressivamente, foram percebendo possibilidades profissionais antes não previstas enquanto escolha.

Também as atividades expositivas possibilitaram criar um maior dinamismo no espaço monótono da escola, cujos corredores em tons de verde, segundo os estudantes, "fazem lembrar um hospital". Partindo da ideia da valorização da cultura visual, da imagem e da sua contemplação, as exposições centraram-se em imagens e cartazes em formato permanente e impresso. Através da apresentação do objeto visual num contexto amplo, ordenado e enquadrado, procurou-se criar uma valorização da mensagem visual numa época em que a sua observação parece estar reduzida à dimensão diminuta dos ecrãs de telemóvel. Assim, existiu uma preocupação em sensibilizar sobre as temáticas expostas, de forma física e permanente, já que os materiais ficavam visíveis ao longo do tempo para lá da sua visualização automática e da partilha automatizada nas redes sociais.

Finalmente, as visitas efetuadas a museus, nomeadamente os de arte contemporânea, bem como o dinamismo criado na escola através dos trabalhos de grupo focados na preparação de exposições permitiu, também, a consolidação por parte dos estudantes de competências relativas à sua formação cívica.

\section{Considerações finais}

Procurou-se neste texto documentar um caso de utilização das atividades expositivas enquanto ferramenta pedagógica, para benesse dos estudantes do curso de Património e Turismo e da comunidade educativa em causa. Com efeito, foi apresentado um processo de ensino feito com recurso a atividades de carácter expositivo, processo que foi ajustado aquando da perceção de que as tradicionais visitas de estudo a museus eram um formato de atividade pedagógica com benefícios limitados. Porém, o processo surge igualmente como resposta à existência na escola de um sistema de ensino demasiado formal. Assim, desenvolveu-se um processo no qual as visitas de estudo continuaram a ser realizadas, mas integradas em projetos pedagógicos mais complexos e complementadas com a realização de exposições dentro do espaço escolar. Esta 
Pereira, Sérgio (2020). Discursos expositivos enquanto recurso pedagógico: análise de uma experiência escolar desenvolvida entre 2006 e 2017. In Alice Duarte (ed.), Seminários DEP/FLUP vol. 1. Porto: Universidade do Porto, Faculdade de Letras/DCTP, p. 118-140. https://doi.org/10.21747/9789898969682/seminariosv1a6

dinâmica centrada na criação de atividades expositivas permitiu desenvolver a componente prática da disciplina.

Embora este processo de ensino/aprendizagem criado tenha sido uma forma de colmatar os problemas existentes no âmbito da docência da disciplina, no decorrer das novas atividades, novas dificuldades foram surgindo, relacionadas ainda com as características do contexto escolar, com o enquadramento económico-social existente e com a forma de funcionamento oferecida pelos museus. Da explicação dessas dificuldades conclui-se que os museus podem desenvolver formas de trabalho promotoras de uma maior participação efetiva do público escolar nas suas atividades. O processo educativo aqui exposto foi ganhando forma após a constatação de que os museus ainda não implementam os ideais da Nova Museologia tanto quanto seria desejável, o que seria útil quer para o museu, quer para o público escolar. É certo que, para tal não acontecer, certamente contribuem os diversos constrangimentos que afetam o contexto de trabalho dos profissionais de serviço educativo. Porém, dessa perceção surgiu a decisão de implementar no espaço da escola técnicas de ensino enquadradas nas abordagens trazidas por esta nova visão sobre o trabalho museológico.

Este processo renovado de ensino resultou, assim, da articulação entre as técnicas formais e informais de ensino, sendo possível identificar os seus contributos positivos. Os estudantes diretamente envolvidos puderam beneficiar de metodologias pedagógicas mais desafiantes e propícias ao desenvolvimento de competências individuais; a escola beneficiou com as exposições criadas enquanto contributo ao serviço da promoção cultural como forma de valorização do espaço escolar. Por fim, o desenvolvimento destas práticas foram igualmente um contributo em termos pessoais para o docente, em termos de criatividade e busca de motivação para a prática da profissão. Este investimento em atividades ligadas aos museus, ao património e às exposições, enquadradas na atividade de docente, ajudou a desenvolver um interesse pessoal que contribuiu para o prosseguimento de estudos ao nível de $3{ }^{\circ}$ ciclo nestas áreas. 
Pereira, Sérgio (2020). Discursos expositivos enquanto recurso pedagógico: análise de uma experiência escolar desenvolvida entre 2006 e 2017. In Alice Duarte (ed.), Seminários DEP/FLUP vol. 1. Porto: Universidade do Porto, Faculdade de Letras/DCTP, p. 118-140. https://doi.org/10.21747/9789898969682/seminariosv1a6

\section{Referências Bibliográficas}

Allard, M. \& Boucher, S. (1998). Éduquer au musée: un modèle théorique de pédagogie muséale. Montréal: Hurtibise $\mathrm{HMH}$.

Ascenção, Viviane (2012). A natureza da pedagogia nos museus: a realidade portuguesa - procura e identificação de modelos. Dissertação de Mestrado. Faculdade de Letras da Universidade de Lisboa.

Bennett, Tony (1995). The Birth of the Museum. London: Routledge.

Clifford, James (2016). Museus como zonas de contato. Alexandre, B. \& Valquíria, P. (trad.). Periódico Permanente, vol. 4, n. 6, p. 1-37.

Duarte; Alice (2013). Nova Museologia: os pontapés de saída de uma abordagem ainda inovadora. Revista Museologia e Patrimônio, vol. 6, n. 2, p. 99-117. [Consult. 25 fev. 2020]. [Disponível em: https://core.ac.uk/download/pdf/143404132.pdf ]

Durval Filho (2006). Museu: de espelho do mundo a espaço relacional. Tese de Mestrado em Ciência da Informação. Escola de Comunicações e Artes da Universidade de São Paulo. São Paulo 2006 [Consult. 20 mai. 2020]. [Disponível em: https://teses.usp.br/teses/disponiveis/27/27151/tde-30112006105557/publico/museus-espaco-relacional.pdf ]

Hernández, Francisca (2006). Planeamientos teóricos de la museologia. Gijón: Ediciones Trea.

ICOM (2015). Definição de Museu [Consult. 20 mai. 2020]. Disponível em http://icomportugal.org/2015/03/19/definicao-museu/ ]

ICOM (2004). Código de Ética do ICOM para Museus. [Consult. 02 dez .2017]. Disponível em http://icom-portugal.org/multimedia/File/Cdigo\%20tica\%20-\%202007\%20\%20verso\%20final\%20pt.pdf ]

ICOM (1984). Declaração de Quebec: Princípios de base de uma nova museologia. [Consult. 20 mai .2020]. Disponível em http://www.minom-portugal.org/docsquebec1974.pdf ]

MacDonald, Sharon (2006). Expanding museum studies: an introduction. In S. MacDonald (ed.), A Companion to Museum Studies. Blackweel Publishing. Oxford, UK, p. 1-12.

Mendes, J. Amado (2013). Museus e Educação. Estudos do Património: Humanidades. Coimbra: Faculdade de Letras da Universidade de Coimbra. 
Pereira, Sérgio (2020). Discursos expositivos enquanto recurso pedagógico: análise de uma experiência escolar desenvolvida entre 2006 e 2017. In Alice Duarte (ed.), Seminários DEP/FLUP vol. 1. Porto: Universidade do Porto, Faculdade de Letras/DCTP, p. 118-140. https://doi.org/10.21747/9789898969682/seminariosv1a6

Moana, Soto (2014). Dos gabinetes de curiosidades aos museus comunitários: a construção de uma conceção muesal à serviço da transformação social. Cadernos de Sociologia, vol. 48, n. 4, p. 57-81.

Nunes, João (2010). Museologias e nova museologia. Os exemplos dos Museus das Santas Casas da Misericórdia. Coimbra: Faculdade de Letras da Universidade de Coimbra/Centro de Estudos Interdisciplinares do Séc. XX. [Consult. 25 fev. 2020]. [Disponível em:

https://estudogeral.sib.uc.pt/bitstream/10316/46215/1/Museologias\%20e\%20 nova\%20museologia.pdf ]

Silverman, Lois (2010). The Social Work of Museums. Londres: Routledge.

Simon, Nina (2010). The Participatory Musem. Santa Cruz, USA: Museum20.

Witcomb, Andrea (2003). Re-imagining the museum: beyond the mausoleum. Londres: Routledge. ISBN: $9780415220989 F O ́ S S E I S:$ que Património? 